\title{
Effect of oil globule size on water exchange mechanism in water-in-oil-in-water emulsions
}

L. Vermeir, ${ }^{*}$ M. Balcaen, A. Declerck and P. Van der Meeren

Ghent University, PalnT (Particle and Interfacial Technology group), Faculty of Bioscience Engineering, Coupure Links 653,9000 Ghent, Belgium. Corresponding Author: Lien.Vermeir@UGent.be; Mathieu.Balcaen@UGent.be; Arnout.Declerck@UGent.be;

Paul.VanderMeeren@UGent.be

The effect of oil globule size of a 20/20/60 (w/w/w) Water-in-Oil-in-Water double emulsion on water transport was investigated for two measurement temperatures using low-resolution ${ }^{1} \mathrm{H}$ pulsed field gradient NMR diffusometry. The measured water diffusion signals were evaluated using available data analysis procedures, which revealed that water exchange mainly occurred between the inner and outer water phase through the oil phase of a double emulsion, provided that the oil globule size was small (about $6 \mu \mathrm{m})$ and the measurement temperature was high $\left(35^{\circ} \mathrm{C}\right)$. For the double emulsion with approximately $50 \mu \mathrm{m}$ sized oil globules or using a low measurement temperature of $5^{\circ} \mathrm{C}$, water exchange happened mainly between the inner water phase and the oil phase within the oil globules of the double emulsion.

\section{Introduction}

Upon replacing part of the oil phase in an Oil-in-Water $(\mathrm{O} / \mathrm{W})$ emulsion, a less energy-dense Water-in-Oil-in-Water (W/O/W) double emulsion is created. Optimization of double emulsion formulation and control of its stability and functionality require the determination of the enclosed water volume fraction. Hereby, low-resolution ${ }^{1} \mathrm{H}$ pulsed field gradient NMR diffusometry has been applied as a non-destructive method ${ }^{1}$. We have recently shown that molecular transport of water molecules through the oil layer of W/O/W emulsions can be detected using diffusion $\mathrm{NMR}^{2}$. This type of water transport became more important when raising the measurement temperature and NMR diffusion delay time $\Delta$. Our previous results have also shown that water transport in double emulsions with large oil globule sizes (about 50 um in diameter) mainly occurred between the inner water phase and the oil phase ${ }^{2}$, whereas other authors ${ }^{3,4}$ described the exchange between the internal and external water phase. Therefore, it is interesting to evaluate whether the oil globule size of the W/O/W emulsion might explain the difference in observed water transport mechanism. To that end, the NMR diffusion data of two types of W/O/W emulsions, one with large oil globules and one with smaller oil globules (and hence, with smaller distance between the two water phases), were measured at 5 and $35^{\circ} \mathrm{C}$ at different $\Delta$-values. Detailed analysis of the diffusion signals allows to evaluate the water transport mechanism.

\section{Materials and methods \\ Materials}

The lipophilic emulsifier polyglycerol polyricinoleate (PGPR 4150) and the hydrophilic emulsifier sodium caseinate were kindly provided by Palsgaard A/S (Denmark) and Armor Protéines (Saint Brice en Cogles, France), respectively. High oleic sunflower oil (Hoso; lodine Value=87; 82\% C18:1) was acquired from Contined B.V. (Bennekom, The Netherlands). The 0.1 M phosphate buffer solution ( $\mathrm{pH}$ 6.7) contained $0.02 \%(\mathrm{w} / \mathrm{v})$ of the anti-microbial agent $\mathrm{NaN}_{3}$ (Acros Organics, Geel, Belgium), $\mathrm{KH}_{2} \mathrm{PO}_{4}$ (Merck $\mathrm{KGaA}$, Darmstadt, Germany) and $\mathrm{K}_{2} \mathrm{HPO}_{4}$ (Alfa Aesar, Karlsruhe,
Germany). All above mentioned chemicals were of analytical grade.

\section{Water-in-oil emulsion}

An Ultra-Turrax (type S 50 N - G 45 F, IKA ${ }^{\circledR}$-Werke, Germany) and a Microfluidizer (type M110S, Microfluidics) at 840 bar (driving air pressure of 6 bar) for 1.5 min were used to premix and homogenize the $\mathrm{W}_{1} / \mathrm{O}$-emulsion $(50: 50, \mathrm{w} / \mathrm{W})$ at $60^{\circ} \mathrm{C}$, respectively. The primary water phase $\left(\mathrm{W}_{1}\right)$ contained $1.25 \%(\mathrm{w} / \mathrm{v})$ sodium caseinate and the $0.1 \mathrm{M}$ phosphate buffer solution, whereas the oil phase consisted of 2.5 wt\% PGPR in Hoso.

\section{Water-in-oil-in-water emulsion}

The external water phase $\left(W_{2}\right)$ that only differs from the $W_{1}$-phase in the concentration of sodium caseinate $(1 \%, \mathrm{w} / \mathrm{v})$, was mixed at room temperature with freshly prepared $W_{1} / O$-emulsion in a ratio 60:40 $(\mathrm{w} / \mathrm{w})$. For preparation of a double emulsion with large oil globules (L-W/O/W), an Ultra-Turrax S25-10G (IKA ${ }^{\circledR}$-Werke, Germany) at $24000 \mathrm{rpm}$ for 5 minutes was used, whereas for preparation of a double emulsion with small oil globules (S-W/O/W) an Ultra-Turrax S25KV-25G (IKA ${ }^{\circledR}$-Werke, Germany) at 6500 rpm for 1 minute was applied followed by one pass through a Microfluidizer (type M110S, Microfluidics) at $140 \mathrm{bar}$ (driving air pressure of 1 bar). The size of the oil globules in the double emulsion was analysed by a Malvern Mastersizer 3000 (Malvern Instruments) whereby the refractive indices were set at $1.5295+0.01 \mathrm{i}$ and 1.33 according to presentation code 3OFD in the software. The volume-weighted mean diameter $D_{43}$ of the S-W/O/W and L-W/O/W emulsion amounted to $5.7 \pm 0.2 \mu \mathrm{m}$ and $48.3 \pm 0.2 \mu \mathrm{m}(n=3)$, respectively.

\section{Low-resolution ${ }^{1} \mathrm{H}$ pulsed field gradient NMR diffusometry}

NMR measurements were performed at 5 and $35^{\circ} \mathrm{C}$ on a benchtop Maran Ultra spectrometer (Oxford Instruments, UK) operating at a frequency of $23.4 \mathrm{MHz}$. The samples were filled in cylindrical glass NMR tubes (outer diameter $18.0 \mathrm{~mm}$; inner diameter $15.2 \mathrm{~mm}$; 
Oxford Instruments, UK) up to $15 \mathrm{~mm}$ and elevated for $27 \mathrm{~mm}$ above the bottom using a Teflon spacer, so that they did not exceed the active region of the Radio Frequency coil.

For a description of ${ }^{1} \mathrm{H}$ pulsed field-gradient (PFG) NMR diffusometry experiments, we refer to Johns ${ }^{5}$ and Voda and van Duynhoven ${ }^{6}$. PFG-NMR experiments were performed using the stimulated echo pulse (STE) sequence ${ }^{1}$, which was preceded by an inversion recovery experiment for suppression of the NMR-contribution from the fat phase in the emulsion, characterized by a time period $\mathrm{T}_{\text {null }}{ }^{7}$. At 5 and $35^{\circ} \mathrm{C}$, the $\mathrm{T}_{\text {null }}$-value of the oil phase amounted to $40 \mathrm{~ms}$ and $103 \mathrm{~ms}$, respectively. Measurements were performed varying the gradient strength $(G)^{8}$ between 0 and $3.17 \mathrm{~T} / \mathrm{m}$ while keeping the gradient duration $(\delta)$ constant $(2.5 \mathrm{~ms})$ and the diffusion delay $(\Delta)$ fixed for values between 60 and $220 \mathrm{~ms}$.

The free self-diffusion coefficient of the water phase was measured $\left(D_{s}\right)$ using the DSD script (Oxford Instruments, UK) and varying $\delta$ between 0.05 and $2.75 \mathrm{~ms}$ while keeping $G$ and $\Delta$ constant at $0.14 \mathrm{~T} / \mathrm{m}$ and $200 \mathrm{~ms}$, respectively. $D_{s}$ of the $W_{1}$ phase amounted to $1.2 \times 10^{-9}$ and $2.8 \times 10^{-9} \mathrm{~m}^{2} / \mathrm{s}$ at 5 and $35^{\circ} \mathrm{C}$, respectively.

Water diffusion signal of two independent water compartments of quasi free and restricted diffusion. Differences in diffusion behaviour in W/O/W emulsions allow discriminating between internal and external water. Water molecules in the external water phase experience quasi free diffusion (FW) (with a minor obstruction effect due to the oil globules present) characterized by $D_{\mathrm{e}}$, whereas the diffusion in the internal water droplets is restricted. The latter can be described by the Murday and Cotts ${ }^{6,9,10}$ equation $E_{\mathrm{MC}}$, assuming that the diffusion of the inner water droplets, as well as the water exchange through the oil or fat phase is negligible during the analysis. Provided that the two water compartments can be regarded as independent, a combination of a fast and slow echo decay is recorded at low and high values of $q^{2}$, respectively, characterized by a quasi bi-component decay ${ }^{2} E_{\text {MCFW }}$ (Eq. 1) as a function of $q^{2}$ and diffusion delay $\Delta$.

$$
\begin{aligned}
E_{\text {MCFW }}\left(q^{2}, \Delta\right)=\frac{l}{l_{0}}= & E V \cdot \frac{\int_{0}^{\infty} P_{v}(R) \cdot E_{M C}\left(R, q^{2}, \Delta\right) d R}{\int_{0}^{\infty} P_{v}(R) d R}+ \\
& (1-E V) \cdot \exp \left(-q^{2} \cdot\left(\Delta-\frac{\delta}{3}\right) \cdot D_{e}\right)
\end{aligned}
$$

The amplitudes of the echo decay yield the enclosed water volume fraction (EV), which is the fraction of the total water that is present as internal water droplets. To account for polydisperse droplet sizes $^{11}$, the normalized attenuation of the NMR signal $I / I_{0}$ of the population of possible spherical droplet radii $R$ with a certain probability $P_{v}$ can be described by the first term in Eq. 1 . Hereby, $P_{v}$ is usually modelled by a lognormal volume-weighted particle size distribution $^{2,6,10}, I_{0}$ is the echo intensity in the absence of a magnetic field and $q$ is a function of the gyromagnetic ratio $\gamma\left(2.675 \times 10^{8} \mathrm{~s}^{-1} \mathrm{~T}^{-1}\right)$, the gradient duration $\delta$ and the gradient strength $G$ according to $q=\delta \cdot \gamma \cdot G$.

Water diffusion signal of two dependent water compartments with exchange between the inner and outer water phase through the oil layer. A schematic representation and simulation of the normalized NMR echo decay as a function of $q^{2}$ using an exchange model as described by Pfeuffer et al. ${ }^{12}$ and Schoberth et al. ${ }^{13}$ is shown in Fig. 1a:

$$
E_{P f}\left(q^{2}, \Delta\right)=p_{1}^{\prime} \cdot \exp \left(-q^{2} \cdot\left(\Delta-\frac{\delta}{3}\right) \cdot D_{1}^{\prime}\right)+p_{2}^{\prime} \cdot \exp \left(-q^{2} \cdot\left(\Delta-\frac{\delta}{3}\right) \cdot D_{2}^{\prime}\right)
$$

The simulated echo decay is characterized by two slopes and hence, two contributions. Hereby, the fast decaying part increases for increasing $\Delta$, whereas the slower part remains constant, but its amplitude decreases as attributed to extra-droplet diffusion of water through the oil layer inside the multiple droplets, as well as between the inner and outer water compartment. This statement is valid as long as there is exchange between the two water phases during the diffusion time $\Delta$ (dashed lines in Fig. 1a). The apparent water volume fractions $p_{1,2}^{\prime}$ and apparent diffusion coefficients of the inner and outer water compartments $D_{1,2}^{\prime}$ are functions ${ }^{10,12}$ of their real values $\left(p_{1,2}\right.$ and $\left.D_{1,2}\right)$ and the mean residence time $\left(T_{1,2}\right)$ of water in the inner and outer water pool. Hereby, $D_{1}$ is related to the inner compartmental size distribution $P_{\mathrm{v}}$ and $p_{1}$ equals $E V$.

Water diffusion signal of two independent water compartments with exchange between the inner water phase and oil layer. The simulated signal decays strongly change when water exchange between the two water phases is negligible during $\Delta$, but primarily occurs between the inner water droplets and the oil

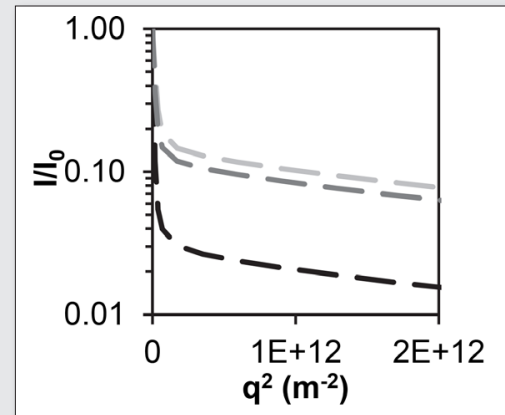

(a)

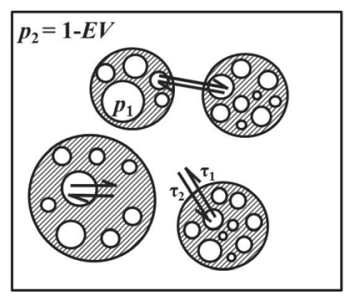

(b)
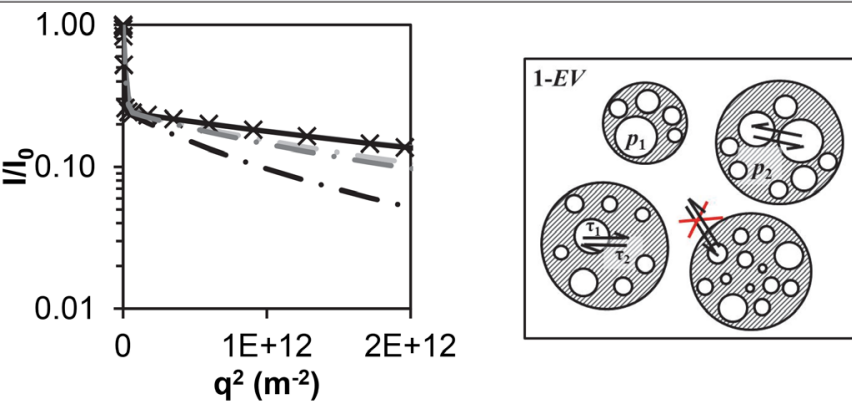

Figure 1. Schematically drawn systems and simulated normalized echo decay of a 20/20/60 (w/W/W) W/O/W emulsion using (a) Eq. 2, $\mathrm{T}_{1}=0.10 \mathrm{~s}(--)$, $E V=25 \%$, water diffusion coefficient in the external water compartment $=1.1 \times 10^{-9} \mathrm{~m}^{2} / \mathrm{s}$ for $\Delta=60 \mathrm{~ms}$ (light grey), $80 \mathrm{~ms}$ (dark grey) and $\Delta=220 \mathrm{~ms}$ (black). (b) Using Eq. 3, with $E V=25 \%$, water fraction in the oil compartment $=1 \%, D_{2}=4 \times 10^{-10} \mathrm{~m}^{2} / \mathrm{s}$ and $D_{e}=1.1 \times 10^{-9} \mathrm{~m}^{2} / \mathrm{s}$, the following echo decays were simulated for $\mathrm{T}_{1}=0.10 \mathrm{~s}(-\cdot-)$ and $\Delta=60 \mathrm{~ms}$ (light grey), $\Delta=80 \mathrm{~ms}$ (dark grey) and $\Delta=220 \mathrm{~ms}$ (black); $\mathrm{T}_{1}=30 \mathrm{~s}$ and $\Delta=60 \mathrm{~ms}(-) ; \mathrm{T}_{1}=30 \mathrm{~s}$ and $\Delta=220 \mathrm{~ms}(\mathrm{x})$. For both equations, the values characterizing $P_{\mathrm{v}}$ were kept identical. 
phase (schematic and dashed-dotted lines in Fig. 1b), for which the extended exchange model (with a quasi free water diffusion term characterized by $D_{\mathrm{e}}$ ) can be applied ${ }^{2}$ :

$E_{P f F W}\left(q^{2}, \Delta\right)=\frac{l}{I_{0}}=E V \cdot E_{P f}\left(q^{2}, \Delta\right)+(1-E V) \cdot \exp \left(-q^{2} \cdot\left(\Delta-\frac{\delta}{3}\right) \cdot D_{e}\right)$

The extrapolated value for $q \rightarrow 0$ reflects the relative amplitudes of inner and outer water phases which should be independent of the values of the experimental NMR parameters. The two populations in the Pfeuffer contribution in Eq. 3 correspond to the internal water in the droplets and (a small amount of) water present in the surrounding oil phase. In case of an infinitely long mean residence time of water in the inner water compartment (i.e. no exchange), the curves of Eq. 3 and Eq. 1 will appear similar (Fig. 1b, $\mathrm{T}_{1}=30 \mathrm{~s}$ ).

The best fitted values for $E V$ (and $I_{0}$ and $P_{\mathrm{v}}$ ) are obtained upon performing a least-squares fit of the equations to the echo intensity data using Matlab 7.5.0.342 (R2007b) software (The MathWorks). In addition, the use of Eqs. 2 and 3 results in values of $T_{1}$, water volume fractions and water diffusion coefficients in the considered compartments. The fit to the relative trend was measured as the adjusted $R^{2}$-value.

\section{Results and discussion}

The diffusion echo signal decays of the S-W/O/W and L-W/O/W emulsion as measured at 60,80 and $220 \mathrm{~ms}$ and 5 and $35^{\circ} \mathrm{C}$ are shown in Fig. 2.

With respect to the $\mathrm{L}-\mathrm{W} / \mathrm{O} / \mathrm{W}$ emulsion as measured at $5^{\circ} \mathrm{C}$ (Fig. 2a) and more pronouncedly at $35^{\circ} \mathrm{C}$ (Fig. 2C), the slope of the slowly decreasing part of the echo decay increased as the diffusion delay was increased and showed a common intercept. The former points to considerable extra-droplet transport within the multiple droplets, whereas the latter indicates that the exchange between the inner and outer water compartment was negligible within the time frame considered (i.e. two independent water compartments). The change of the echo decay as a function of $\Delta$ sustains the use of Eq. 3 to fit the diffusion data of L-W/O/W at $35^{\circ} \mathrm{C}$ (Fig. 2c, dasheddotted lines, $R_{\text {adj }}^{2}=0.99$ ). The resulting best fitted $\mathrm{T}_{1}$, enclosed water volume fraction $E V$, water fraction in the oil compartment, water diffusion coefficient in the oil compartment $\left(D_{2}\right)$ and water diffusion coefficient in the external water compartment $\left(D_{\mathrm{e}}\right)$ amounted to $0.05 \mathrm{~s}, 23.7 \%, 2.8 \%, 4.9 \times 10^{-10} \mathrm{~m}^{2} / \mathrm{s}$ and $1.6 \times 10^{-9} \mathrm{~m}^{2} / \mathrm{s}$, respectively. For the sake of completeness, the best fitted values for the $\mathrm{L}-\mathrm{W} / \mathrm{O} / \mathrm{W}$ emulsion at $5^{\circ} \mathrm{C}$ using Eq. 3 (Fig. 2a, dashed-dotted lines, $\left.R_{\text {adj }}^{2}=0.98\right)$ amounted to $0.12 \mathrm{~s}, 23.7 \%, 5.0 \%, 4.7 \times 10^{-11} \mathrm{~m}^{2} / \mathrm{s}$ and $1.1 \times 10^{-9} \mathrm{~m}^{2} / \mathrm{s}$, respectively. As compared to $35^{\circ} \mathrm{C}$, the smaller

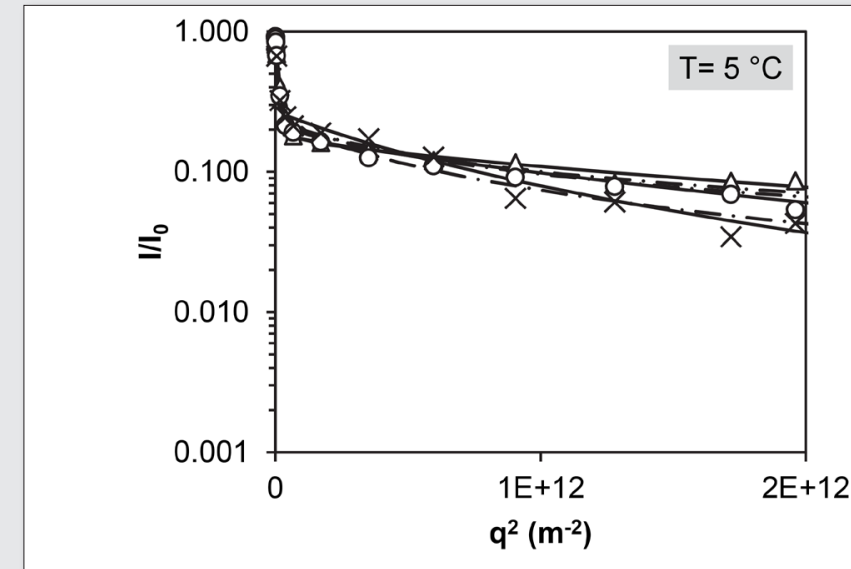

(a)

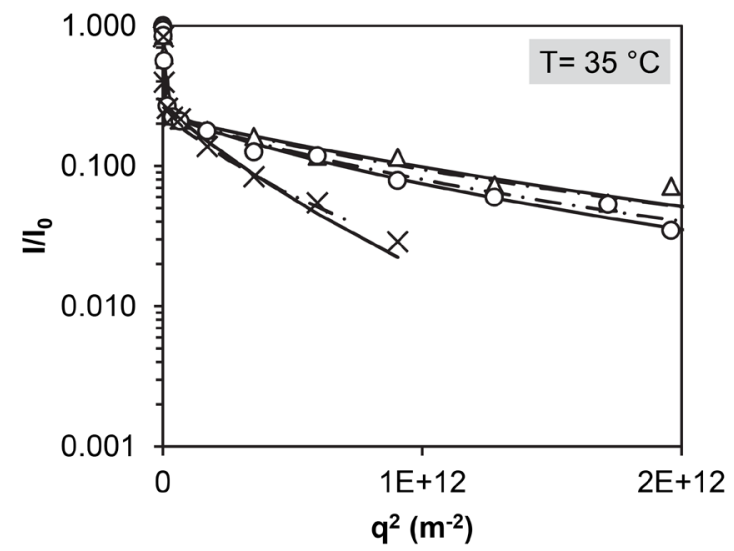

(c)

Figure 2. Diffusion echo decay of the L-W/ON (a-c) and S-W/ON (b-d) emulsion as measured at $5^{\circ} \mathrm{C}(\mathrm{a}-\mathrm{b})$ and $35^{\circ} \mathrm{C}(\mathrm{c}-\mathrm{-}-\mathrm{d})$ using $\Delta=60(\triangle), 80(\mathrm{O})$ and $220 \mathrm{~ms}(\mathrm{x})$. Full black lines indicate the fitting of a non-exchange model (Eq. 1) to the data, the dashed lines indicate the fitting of the two dependent water compartmental model (Eq. 2), the dashed-dotted line indicates the fitting of a model for two independent water compartments with exchange between the inner water phase and oil layer (Eq. 3) and the grey lines indicate the linear regression analysis of the slow decay of S-W/O/W at $35^{\circ} \mathrm{C}$. 
values of the diffusion coefficients at $5^{\circ} \mathrm{C}$ are explained by the Stokes Einstein equation, whereas the larger $\mathrm{T}_{1}$ (or lower exchange rate $\mathbf{T}_{1}^{-1}$ ) is related to a decrease in solubility and diffusivity of water through oil with decreasing measurement temperature ${ }^{2}$.

As compared to the $\mathrm{L}-\mathrm{W} / \mathrm{O} / \mathrm{W}$ emulsion at $35^{\circ} \mathrm{C}$, the diffusion signals of the S-W/O/W emulsion as measured at $5{ }^{\circ} \mathrm{C}$ showed the same features as a function of $\Delta$. Upon fitting Eq. 3 to the diffusion data (Fig. 2b, dashed-dotted lines, $R_{\text {adj }}^{2}=0.99$ ), the best fitted $\mathrm{T}_{1}, E V$, water fraction in the oil compartment, $D_{2}$ and $D_{\mathrm{e}}$ amounted to 0.13 $\mathrm{s}, 11.3 \%, 4.8 \%, 6.0 \times 10^{-10} \mathrm{~m}^{2} / \mathrm{s}$ and $0.9 \times 10^{-9} \mathrm{~m}^{2} / \mathrm{s}$, respectively. As compared to the double emulsion with larger oil globules, the smaller enclosed water volume fraction of the S-W/O/W emulsion follows from the application of a high-energetic homogenization treatment, which partially destroys the primary W/O emulsion, next to reducing the oil globule size of the double emulsion ${ }^{14}$.

As shown in Fig. 2d, the diffusion signal of the S-W/O/W emulsion as measured at $35^{\circ} \mathrm{C}$ attenuated much more and showed the typical features of a double emulsion with water exchange between the inner and outer water phase (i.e. intercept of the slow decay decreased with increasing $\Delta$, whereas its slope remained constant with $\Delta$ ), as well as water exchange through the oil layer within the multiple droplets. This sustains the use of Eq. 2 (two dependent water compartmental model) to fit the diffusion data (Fig. 2d, dashed lines, $R_{\text {adj }}^{2}=0.99$ ). The resulting best fitted $\mathrm{T}_{1}, E V$ and water diffusion coefficient in the external water compartment amounted to $0.15 \mathrm{~s}, 7.4 \%$ and $1.5 \times 10^{-9} \mathrm{~m}^{2} / \mathrm{s}$, respectively. Hereby, the small enclosed water volume fraction was in line with the value as estimated for the S-W/O/W emulsion at $5^{\circ} \mathrm{C}$.

It is interesting to evaluate the results of applying a non-exchange model (Eq. 1) to the diffusion data of a double emulsion with molecular water transport (Fig. 2a,b,c, solid lines, $R_{\text {adj }}^{2}>0.99$ ). The average best fitted water diffusion coefficient in the external water compartment $\left(D_{\mathrm{e}}\right)$ at 5 and $35^{\circ} \mathrm{C}$ amounted to $1.1 \times 10^{-9}$ and $2.5 \times 10^{-9} \mathrm{~m}^{2} / \mathrm{s}$, respectively. The best fitted $E V$-values are given in Fig. 3. Due to the large echo decay of S-W/O/W at $35^{\circ} \mathrm{C}$, it was not possible to use Eq. 1 to fit the data, for which the EV-value was calculated using Eq. 4. Hereby, the natural logarithm of the echo intensity of the slow decay was linearly extrapolated to $q^{2}=0 \mathrm{~m}^{-2}\left(R^{2}>0.72\right)$. It is worth mentioning that this approach can be employed for double emulsions with a narrow inner water droplet size distribution. The extrapolated $I_{0}$-value was compared to the experimentally obtained $I_{0}$-value at $\mathrm{G}=0 \mathrm{~T} / \mathrm{m}$ as follows:

$$
E V(\%)=\frac{I_{0, \text { extrapolated }}}{I_{0, \text { experimental }}} \cdot 100 \%
$$

When water transport occurs between the two water compartments during the diffusion measurements, the amplitudes of Eq. 1 will only yield an apparent EV-value. The real enclosed water volume fraction might be approximated by extrapolation of the apparent values to zero diffusion delay $(\Delta=0 \mathrm{~ms})^{1}$. For the L-W/O/W emulsion at 5 and $35^{\circ} \mathrm{C}$ and for the S-W/O/W emulsion at $5^{\circ} \mathrm{C}$, the measured $E V$-values hardly changed with increasing $\Delta$ (Fig. 3). The respective slopes amounted to $-0.01 \pm 0.02 \% \cdot \mathrm{ms}^{-1},-0.01 \pm 0.01 \% \cdot \mathrm{ms}^{-1}$ and $-0.01 \pm 0.01 \% \mathrm{~ms}^{-1}$. Consequently, the extrapolated $E V$-values (with 95\% confidence interval) to $\Delta=0 \mathrm{~ms}$ approximated the measured $E V$-values and amounted to $20.8 \pm 2.9 \%, 24.1 \pm 0.1 \%$ and $10.8 \pm 1.4 \%$, respectively. It is worth noting that these values correspond quite well to the above mentioned ones as obtained using

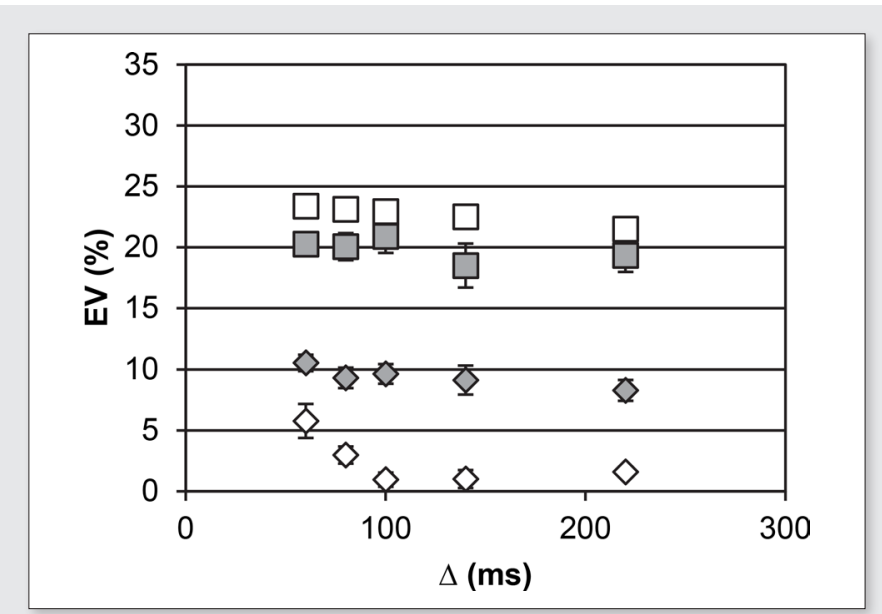

Figure 3. Best fitted (apparent) enclosed water volume fraction EV of the $\mathrm{L}-\mathrm{W} / \mathrm{O} \mathrm{W}(\square)$ and $\mathrm{S}-\mathrm{W} / \mathrm{O} / \mathrm{W}(\diamond)$ emulsion as measured at $5^{\circ} \mathrm{C}$ (grey markers) and $35^{\circ} \mathrm{C}$ (white markers) as obtained using Eq. 1 (and Eq. 4 in case of S-W/ON at $35^{\circ} \mathrm{C}$ ). Error bars denote the standard error of the estimate.

Eq. 3. These results further sustain the dominant occurrence of water exchange between the inner water phase and oil phase during the time frame of the diffusion analysis of the L-W/O/W emulsion as measured at 5 and $35^{\circ} \mathrm{C}$, as well as of the S-W/O/W emulsion at $5^{\circ} \mathrm{C}$, rather than by exchange between the inner and outer water phase of the double emulsion.

On the other hand, the (apparent) $E V$-values of the double emulsion with smaller oil globules (S-W/O/W) as measured at $35^{\circ} \mathrm{C}$ strongly decreased as a function of $\Delta$, whereby near-zero apparent $E V$-values were obtained at $\Delta>100 \mathrm{~ms}$ (Fig. 3). The strong $\Delta$-dependency of the $E V$-value further shows that the water diffusion occurred between the two water compartments through the oil film of the double emulsion during time $\Delta$.

Hereby, the results indicate that the difference in water transport mechanism arises from the difference in distance $(Z)$ as travelled by the water molecules through the oil layer, which depends on the temperature dependent diffusion coefficient $(D)$ of water through the oil layer, as well as on the diffusion observation time $\Delta$ according to $\Delta=Z^{2} / D$. Hereby, the maximum $Z$-value amounts to $0.5 \times D_{43}$ for water molecules in the inner water droplets as located in the centre of the oil globule. Using a $D$-value of $0.01 \times 10^{-11} \mathrm{~m}^{2} / \mathrm{s}$ and $1.11 \times 10^{-11} \mathrm{~m}^{2} / \mathrm{s}$ at 5 and $35^{\circ} \mathrm{C}^{2}$, the estimated $\Delta$ for the L-W/O/W and S-W/O/W amounted to 5832 and $81 \mathrm{~s}$ at $5^{\circ} \mathrm{C}$, whereas $\Delta$ was 53 and $0.7 \mathrm{~s}$ at $35^{\circ} \mathrm{C}$. These values indicate that at least part of the internal water (as located between the centre and oil globule surface) of the S-W/O/W emulsion at $35^{\circ} \mathrm{C}$ reached the oil globule surface during the largest applied $\Delta(0.220 \mathrm{~s})$ in the experiments, whereas a much smaller fraction reaches the oil globule surface for the other emulsions.

\section{Conclusions}

Low-resolution ${ }^{1} \mathrm{H}$ pulsed field gradient NMR diffusometry was applied to investigate water transport in W/O/W emulsions with different oil globule sizes as measured at different temperatures. The resulting diffusion signals were analysed using the available data analysis procedures that take exchange into account, as well as using a procedure that assumes impermeable droplet boundaries. 
The measurement of the double emulsion with small sized oil globules at a high temperature of $35^{\circ} \mathrm{C}$ indicated that the distance between the inner and outer water compartment was sufficiently short, as well as the mobility of water molecules sufficiently large, for water molecules to bridge the two water compartments during the diffusion time $\Delta$. Regarding the double emulsion with large sized oil globules at $35^{\circ} \mathrm{C}$, water exchange mainly occurred between the inner water phase and the oil phase due to a larger distance between the two water compartments. For the double emulsions with small or large sized oil globules as measured at a lower temperature of $5^{\circ} \mathrm{C}$, the water diffusivity was smaller and hence, the travelled distance of water was limited to the inner water phase and the oil phase within the oil globules.

\section{Acknowledgments}

Research funded by a PhD Grant (111 508) to L.V. of Flanders Innovation \& Entrepreneurship (VLAIO). The authors thank the Fund for Scientific Research-Flanders (FWO Vlaanderen) for their financial support for obtaining the low-resolution 23.4 MHz NMR equipment. We also acknowledge funding from Flanders' Food.

\section{References}

1. L. Vermeir, M. Balcaen, P. Sabatino, K. Dewettinck and P. Van der Meeren, "Influence of molecular exchange on the enclosed water volume fraction of W/O/W double emulsions as determined by low-resolution NMR diffusometry and $\mathrm{T}_{2}$-relaxometry", Colloids and Surfaces A: Physicochemical and Engineering Aspects. 456, 129-138 (2014). doi: http://dx.doi.org/10.1016/j.colsurfa.2014.05.022

2. L. Vermeir, P. Sabatino, M. Balcaen, A. Declerck, K. Dewettinck, J.C. Martins, G. Guthausen and P. Van der Meeren, "Effect of molecular exchange on water droplet size analysis as determined by diffusion NMR: The W/O/W double emulsion case", Journal of Colloid and Interface Science. 475, 57-65 (2016). doi: http://dx.doi.org/10.1016/j. jcis.2016.04.029

3. X. Guan, K. Hailu, G. Guthausen, F. Wolf, R. Bernewitz and H.P. Schuchmann, "Pfg-NMR on $\mathrm{W}_{1} / \mathrm{O} / \mathrm{W}_{2}$-emulsions: evidence for molecular exchange between water phases", European Journal of Lipid Science and Technology. 112, 828-837 (2010). doi: http://dx.doi.org/10.1002/ ejlt.201000022

4. J.P. Hindmarsh, J. Su, J. Flanagan and H. Singh, "PFG-NMR analysis of intercompartment exchange and inner droplet size distribution of W/O/W emulsions". Langmuir. 21, 9076-9084 (2005). doi: http://dx.doi. org/10.1021/la051626b
5. M.L. Johns, "NMR studies of emulsions", Current Opinion in Colloid \& Interface Science. 14, 178-183 (2009). doi: http://dx.doi.org/10.1016/i. cocis.2008.10.005

6. M.A. Voda and van J.P.M. Duynhoven, "Characterization of food emulsions by PFG NMR", Trends in Food Science \& Technology. 20, 533543 (2009). doi: http://dx.doi.org/10.1016/j.tifs.2009.07.001

7. J.P.M. van Duynhoven, G.J.W. Goudappel, G. van Dalen, P.C. van Bruggen, J.C.G. Blonk and A.P.A.M. Eijkelenboom, "Scope of droplet size measurements in food emulsions by pulsed field gradient NMR at low field", Magnetic Resonance in Chemistry. 40, S51-S59 (2002). doi: http://dx.doi.org/10.1002/mrc.1115

8. J.P.M. van Duynhoven, B. Maillet, J. Schell, M. Tronquet, G.J.W. Goudappel, E. Trezza, A. Bulbarello and D. van Dusschoten, "A rapid benchtop NMR method for determination of droplet size distributions in food emulsions", European Journal of Lipid Science and Technology. 109, 1095-1103 (2007). doi: http://dx.doi.org/10.1002/ejlt.200700019

9. J.S. Murday and R.M. Cotts, "Self-diffusion coefficient of liquid lithium", Journal of Chemical Physics. 48, 4938-4945 (1968). doi: http://dx.doi. org/10.1063/1.1668160

10. R. Bernewitz, G. Guthausena and H.P. Schuchmann, "NMR on emulsions: characterization of liquid dispersed systems", Magnetic Resonance in Chemistry. 49, S93-S104 (2011). doi: http://dx.doi. org/10.1002/mrc.2825

11. K.J. Packer and C.J. Rees, "Pulsed NMR studies of restricted diffusion", Journal of Colloid and Interface Science. 40, 216-218 (1972). doi: http:// dx.doi.org/10.1016/0021-9797(72)90010-0

12. J. Pfeuffer, U. Flögel, W. Dreher and D. Leibfritz, "Restricted diffusion and exchange of intracellular water: theoretical modelling and diffusion time dependence of ${ }^{1} \mathrm{H}$ NMR measurements on perfused glial cells", NMR in Biomedicine, 11, 19-31 (1998). doi: http://dx.doi.org/10.1002/ (SICl)1099-1492(199802)11:1<19::AIDNBM499>3.0.CO;2-O

13. S.M. Schoberth, N.-K. Bär, R. Krämer and J. Kärger, "Pulsed High-Field Gradient in vivo NMR spectroscopy to measure diffusional water permeability in Corynebacterium glutamicum", Analytical Biochemistry. 279, 100-105 (2000). doi: http://dx.doi.org/10.1006/abio.1999.4450

14. L. Vermeir, P. Sabatino, M. Balcaen, G. Van Ranst and P. Van der Meeren, "Evaluation of the effect of homogenization energy input on the enclosed water volume of concentrated W/O/W emulsions by lowresolution $T_{2}$-relaxometry", Food Hydrocolloids. 34, 34-38 (2014). doi: http://dx.doi.org/10.1016/j.foodhyd.2013.01.024 